\title{
Event-related potentials elicited by the Deutsch "high-low" word illusion in the patients with first-episode schizophrenia with auditory hallucinations
}

You Xu ${ }^{1 \dagger}$, Hao Chai ${ }^{1 \dagger}$, Bingren Zhang ${ }^{1}$, Qianqian Gao ${ }^{1}$, Hongying Fan ${ }^{1}$, Leilei Zheng ${ }^{2}$, Hongjing Mao ${ }^{3}$, Yonghua Zhang ${ }^{3}$ and Wei Wang ${ }^{1,3^{*}}$

\begin{abstract}
Background: The exact cerebral structural and functional mechanisms under the auditory verbal hallucinations (AVHs) in schizophrenia are still unclear. The Deutsch "high-low" word illusion might trigger attentional responses mimicking those under AVHs.

Methods: We therefore have invited 16 patients with first-episode, paranoid schizophrenia, and 16 age- and gender-matched healthy volunteers to undergo the "oddball" event-related potentials elicited by the illusion. The clinical characteristics of patients were measured with the positive and negative symptom scale.

Results: Besides the longer reaction time to the illusion, the standard P2 latency was shortened, the N2 latency was prolonged, and both $\mathrm{N} 1$ and P3 amplitudes were reduced in patients. The P3 source analyses showed the activated bilateral temporal lobes, parietal lobe and cingulate cortex in both groups, left inferior temporal gyrus in controls, and left postcentral gyrus in schizophrenia. Moreover, the N1 amplitude was positively correlated with the paranoid score in patients.
\end{abstract}

Conclusions: Our results were in line with previous neurophysiological and neuroimaging reports of hallucination or auditory processing in schizophrenia, and illustrated a whole process of cerebral information processing from N1 to P3, indicating this illusion had triggered a dynamic cerebral response similar to that of the AVHs had engaged.

Keywords: Auditory hallucinations, Deutsch "high-low" word illusion, Event-related potentials, Paranoid schizophrenia

\section{Background}

Schizophrenia is a severe mental disorder with persistent perceptual and cognitive impairments $[1,2]$, such as semantic processing deficits [3-5] and attention problems [6]. Auditory hallucinations especially auditory verbal hallucinations (AVHs) are one of the characteristic symptoms of the disorder, which might range from single words or phrases to voices giving commands, comments, insults, or encouragement [7]. Many attempts to understand the

\footnotetext{
* Correspondence: drwangwei@zju.edu.cn

${ }^{\dagger}$ Equal contributors

'Department of Clinical Psychology and Psychiatry, School of Public Health,

Zhejiang University College of Medicine, Hangzhou, China

${ }^{3}$ Department of Clinical Psychology, Mental Health Center, Zhejiang

University College of Medicine, Hangzhou, China

Full list of author information is available at the end of the article
}

neural correlates of AVHs have been trialed in recent years. For instance, the AVHs, with more ambiguous or salient signals often accepted as real and meaningful, were demonstrated broadly involved in the processes of attention, cognition, and emotion of a patient with schizophrenia [8]. It has been shown that the semantic processing of auditory information contributed to the generation of AVHs in a general population [9], but this contribution has not proven in patients with schizophrenia [10].

On the other hand, some scholars consider the relationship between illusion and hallucination, and suggest that the hallucination is the illusion of the reality $[11,12]$. Thus, the illusion-related processing might be used as a specific probe to study AVHs. Deutsch [13] reported a musical illusion, a dichotic listening phenomenon that 
happened when a participant received one sine-wave sequence from one ear and another simultaneously presented but phase-reversed sequence from the other ear, i.e., when one ear received the high tone, the other ear received the low tone and vice versa. In this case, although the high and the low tones were delivered to both ears, righthanded participants typically perceived a single low tone at one ear alternating with a single high tone at the other regardless of how the earphones are positioned [13, 14]. Later, Deutsch [15] used words, such as "high" and "low", to replace the tones, and developed a Deutsch "high-low" word illusion. Listening to this pattern through stereo loudspeakers for a while, English-speaking people had reported hearing English words which were actually not presented, such as "buy loan", "long time", "no, no" and "boatman" [15]; while the healthy Chinese-speaking people and Chinese patients with cluster A personality disorders had reported hearing Chinese words which were related to their personality traits $[16,17]$.

The neuroimaging evidences have suggested that the abnormalities related to auditory hallucinations were in the auditory "what" pathway including anterior and posterior temporal cortices and in the "where" pathway including the superior temporal, inferior parietal and superior frontal cortices $[7,8]$. For instance, the functional neuroimaging studies have associated AVHs with brain areas involved in speech generation, speech perception and auditory processing [18-20]. The areas activated during hallucinations were the temporal and prefrontal cortical areas [21, 22], or the inferior frontal/ insular, anterior cingulate, temporal as well as some subcortical regions [23, 24].

On the other hand, the electroencephalography (EEG) provides noninvasive measures with superior temporal resolution (in milliseconds) of brain activities, and it is more suitable to capture the rapidly occurring processes than the neuroimaging techniques such as fMRI or PET [25]. Using the event-related potentials (ERPs), many hallucinations related cognitive deficits in schizophrenia have been documented. The N4 (N400) potential, considered as a semantic priming related component, has been widely used to explore different aspects of language disturbance in schizophrenia [5], though it was not clear whether this component was a neurophysiological biomarker of the semantic processing dysfunction in schizophrenia $[26,27]$. The $\mathrm{N} 4$ was more negative when examining the processes of context use while it was normal or reduced when examining the primary processes of initial activation within the semantic networks [5]. The component P3 (P300), considered as an attention-related cognitive potential, has also been trialed in illusion studies $[28,29]$. In schizophrenia, the reduced and prolonged P3 component has been consistently observed [30-32], which was also related to the auditory hallucination and clinical symptom severities [33, 34]. More specifically, a left-lateralized reduction of P3 component which was closely related to the decrease of the normal left-dominance function of processing syllables and complex tones [35], was also related to the impairments of the temporal lobe in schizophrenia [34, 36, 37]. Therefore, P3 potential might be one of the endophenotypic markers of schizophrenia [38], and might help to disclose the mechanisms underlying AVHs.

However, due to the difficulty to employ on-going hallucinations (such as AVHs) to trigger an ERP study, there is no investigation illustrating the dynamic changes under AVHs up to date, for instance, in a time window of N1-P3 components. Moreover, since the various AVH contents [7] could hardly be used to trigger an ERP, we would like to adopt the Deutsch "high-low" word illusion as a stimulus in the present study, expecting that the word illusion triggered ERPs indicate the specific pathology of AVHs in schizophrenia. Therefore, we have hypothesized that 1) patients with schizophrenia have a reduced P3 over the scalp topography and 2) there is a prominent cerebral generator responsible for the word illusion processing.

\section{Methods \\ Participants}

Sixteen healthy participants were recruited from medical staff and the community. They were physically healthy, did not suffer from any psychiatric or neurological disorders. Sixteen patients were diagnosed as having paranoid schizophrenia with auditory hallucinations in the acute phase according to the criteria of the International Classification of Diseases-10 [39] after a semistructured clinical interview by two experienced psychiatrists (LZ \& WW) separately. All patients had experienced their first acute episode with relatively short disease durations, and displayed moderate to low levels of psychopathology as accessed using the Positive and Negative Syndrome Scale (PANSS) [40] (Table 1). All participants were confirmed to have no other confounding factors including affective or schizoaffective disorder, nor prior history of head injury, alcohol or tobacco abuse, psychoactive substance abuse, central nervous system inflammation, nor neurocognitive or other disorders influencing the decisional capacity (understanding, appreciation, reasoning, and expression of choice of an action) through the semistructured clinical interview. The demographic data, medical history, and medication information were listed in Table 1 . There was no age $(t=-1.33, p=0.20)$ or gender $\left(\chi^{2}=2.032, p=\right.$ $0.15)$ difference between groups. Six patients were medication free and the remaining patients had been treated with atypical antipsychotics at regular doses for no more than 2 weeks (also see Table 1). A recent CT or MRI scan was available in order to ensure that all patients were free from any organic brain lesions. There was no statistically significant difference in educational level between the two 
Table 1 Demographic data in patients with schizophrenia $(n=16)$ and healthy volunteers $(n=16)$

\begin{tabular}{lll}
\hline & Schizophrenia & Controls \\
\hline Gender (f/m) & $5 / 11$ & $9 / 7$ \\
Age (in years; mean \pm SD/ range) & $22.4 \pm 5.8 / 16-36$ & $20.4 \pm 1.6 / 19-25$ \\
Positive and negative syndrome & & \\
scale (mean \pm SD) & & \\
Total & $59.6 \pm 13.7$ & - \\
Positive scale & $14.4 \pm 4.4$ & - \\
Negative scale & $9.8 \pm 3.7$ & - \\
General psychopathology scale & $31.2 \pm 9.4$ & - \\
Lack of action & $4.63 \pm 1.78$ & - \\
Thinking disorder & $9.31 \pm 2.98$ & - \\
Irritation & $5.69 \pm 2.12$ & - \\
Paranoid & $4.81 \pm 1.38$ & - \\
Depression & $9.81 \pm 2.81$ & - \\
Others & $9.38 \pm 2.50$ & - \\
Disease history (in months) & $2.1 \pm 0.7$ & - \\
Medication & & - \\
olanzapine & 6 & - \\
risperidone & 3 & \\
quetiapine & 1 & - \\
\hline
\end{tabular}

groups. All participants were extreme right-handers according to a Chinese translation of the Edinburgh Handedness Scale [41]. The study was approved by the Ethics Committee of Zhejiang University College of Medicine (No. ZGL201307-2-1). Two PhD candidates (YX \& HC) were available to explain the written informed consent by presenting a Powerpoint presentation, showing a hypothetical EEG experiment onsite, and showing a signed written informed consent to the participants or their next of kin. YX and $\mathrm{HC}$ were also available to aid in the proper filling of the required demographic information, questionnaire and the informed consent, and to ensure corrective feedbacks. In particular, all patients were ensured to have a free expression of choice, and to fully understand the study protocol information (i.e., its atraumatic features, and its usefulness for scientific research and for disease understanding). These patients had to repeat the consent information orally to one experienced psychiatrist (from ZL \& WW) and one PhD candidate (YX \& HC). All adult participants gave their written informed consent to participate. For patients of 16-17 years old, we have obtained the written informed consent by their next of kin, through a surrogate consent procedure, regarding participating in our study. The study also conformed to the Helsinki Declaration concerning human rights and informed consent and followed correct procedures concerning treatment of humans in research.

\section{Stimuli and procedure}

Participants were seated in an armchair in a quiet and dimly lit room while stimuli were delivered according to the "oddball" paradigm through headphones at an interstimulus interval randomized from 1500-2000 ms. The target stimulus was a $250 \mathrm{~ms}$ segment (a full circle) of the "high-low" word illusion [15] and the standard stimulus was a $1000 \mathrm{~Hz}$ tone with the same duration, both edited by Adobe Audition (Adobe Systems Incorporated). The standard stimuli were delivered 160 times (80\%) while the target stimuli were 40 times (20\%) in a randomized order. After a short duration of training, participants were asked to respond to the target stimuli, by pressing a button using the index finger of their artful hand as soon as possible, and their reaction times to the target were recorded. The reaction accuracies for the two groups were all nearly $100 \%$ due to the simplicity of the task.

\section{ERP recording}

The EEG recording were performed with 32 electrodes embedded in an electro-cap (Electro-Cap International, Inc.) according to the 10-20 International System and intermediate positions (Fp1, Fpz, Fp2, F3, F4, F7, F8, Fz, Fc1, Fc2, Fc5, Fc6, T7, T8, C3, C4, Cz, Cp1, Cp2, Cp5, Cp6, P3, P4, P7, P8, Pz, O1, Oz, O2, POz, M1, and M2). Recording was made with the average reference. The EEG was amplified by an ANT amplifier (Enschede, the Netherlands) and the impedance of all electrodes was kept below $10 \mathrm{k} \Omega$. The EEG was continuously recorded with a sampling rate of $1024 \mathrm{~Hz}$ and then re-referred to the average activity of the two mastoid electrodes (M1 and M2) off-line. Trials containing electrooculogram (EOG) and other artefacts were eliminated by ASA software (ANT software, version 4.7., The Netherlands) using a principal component analysis method that models the brain signal and artefact subspaces [42]. Data were filtered with a bandpass of 0.1-30 Hz. Epochs beginning $100 \mathrm{~ms}$ prior to stimulus onset and continuing for $900 \mathrm{~ms}$ were created and segments of the record contaminated by artefacts $( \pm 70 \mu \mathrm{v})$ were rejected from averaging.

ERPs were analyzed in terms of peak latency and baseline-to-peak amplitude of the respective maximal deflections in the following time windows: 50-150 ms and 100-300 ms for standard N1and P2 respectively; 50-150 ms, 100-200 ms, 150-250 ms, 250-400 ms for target N1, P2, N2 and P3 respectively.

\section{Source analyses}

The statistical parametric mapping (SPM 8, http:// www.fil.ion.ucl.ac.uk/spm) toolbox for M/EEG data was used for source analyses of the N1, P2, N2 and P3 components elicited by word illusion segment (i.e., the target) in both groups. The SPM 8 provides "source reconstruction resulting in a spatial projection of sensor data into brain 
space and considers brain activity as comprising a very large number of dipolar sources spread over the cortical sheet based on Bayesian inversion of hierarchical Gaussian process models" [43-45]. In the present study, the SPM default template head model (normal cortical mesh sizes, i.e., 8196 vertices were used for calculating) based on the Montreal Neurological Institute (MNI) brain was used, and the multiple sparse priors algorithm [43] was applied to the time window of each component (again, 50-150 ms, 100-200 ms, 150-250 ms, 250-400 ms for target N1, P2, $\mathrm{N} 2$ and P3 respectively; re-referred to average reference) for the source reconstruction, as this method gives the most plausible results and has greater model evidence [46]. After the reconstruction, a source level statistical analysis based on the random field theory [44, 47] was also performed to detect any significant difference P3 sources between groups.

\section{Statistical analyses}

The mean age and reaction time in the two groups were analyzed by the independent $t$ test. The mean latency/ amplitude of standard N1, P2 and target N1, P2, N2, and P3 at nine electrode sites (F3, Fz, F4, C3, Cz, C4, P3, Pz, and P4) were analyzed using a four-way ANOVA, i.e., Group (2) X Gender (2) X Sagittal Positions (3: frontal, central, and parietal) X Lateral Positions (3: left, central, and right) with the post-hoc Bonferroni test. The mean latency/amplitude difference between two groups at each site were analyzed by the independent $t$ test. The Pearson correlation was applied between latency/amplitude of target N1, P2, N2 and P3 at each site and PANSS scale scores (i.e., total score, positive scale, negative scale, general psychopathology scale, lack of action, thinking disorder, irritation, paranoid, depression, others) in schizophrenia group, while the relationship would not be recognized unless it was significantly at three adjacent sites. The alpha level of significance was set at .05. Based on the design of detecting a group difference in one ERP parameter, for example, the statistical power of our study reached .89 for raw, .95 for column, and .52 for interaction effects.

\section{Results}

The mean reaction time was significantly prolonged $(t=-2.51$, $p=0.02)$ in patients with schizophrenia (384.6 $\mathrm{ms} \pm 90.7)$ compared to that in healthy participants $(317.8 \pm 55.3)$. Each participant clearly showed ERP traces to standard and target stimuli at all 32 electrodes. The grand averages at selected nine electrodes are shown in Fig. 1. Some detailed data, such as the mapping of each potential component, is omitted, for the sake of data presentation brevity.

\section{Morphology triggered by standard stimuli}

In each participant, the N1 and P2 to the standard stimuli were clear.

\section{N1 component}

For standard N1 latencies, no significant main effect of either group $(F(1,28)=1.01, M S E=2073.67, p=0.32)$, gender $(F(1,28)=0.01, M S E=17.30, p=0.93)$, sagittal $(F(2,112)=3.15, \quad M S E=1130.73, p=0.08)$, or lateral $(F(2,112)=0.23, M S E=45.63, p=0.75)$ was detected. For standard N1 amplitudes, no significant group ( $F(1$, $28)=1.60, M S E=52.89, p=0.22)$ effect was detected, but main effect of sagittal $(F(2,112)=42.39, M S E=122.34$, $p<0.01)$, lateral $(F(2,112)=6.33, M S E=6.88, p<0.01)$, and gender $(F(1,28)=6.09, M S E=201.08, p=0.02)$ were all significant. The standard N1 amplitudes were more pronounced at frontal $(-3.9 \mu \mathrm{V} \pm 0.4, p<0.01,95 \% \mathrm{CI}$ $[1.2,2.6])$ and central $(-3.6 \mu \mathrm{V} \pm 0.4, p<0.01,95 \% \mathrm{CI}$ $[1.0,2.0])$ sites compared with those at parietal $(-2.1 \mu \mathrm{V} \pm$ $0.3)$; at central $(-3.3 \mu \mathrm{V} \pm 0.4)$ sites compared with those at left $(-2.9 \mu \mathrm{V} \pm 0.3, p<0.01,95 \% \mathrm{CI}[0.1,0.8])$; and in males $(-4.1 \mu \mathrm{V} \pm 0.5)$ compared with those in females $(-2.3 \mu \mathrm{V} \pm 0.5, p=0.02,95 \%$ CI $[0.3,3.2])$.

\section{P2 component}

For standard P2 latencies, there was significant main effect of group $(F(1,28)=9.81, M S E=62121.12, p<0.01)$, with shortened P2 latencies in schizophrenia (204.1 ms \pm 7.2 ) compared to that in controls $(234.7 \mathrm{~ms} \pm 6.7,95 \% \mathrm{CI}$ $[10.6,50.7])$. Main effect of the gender $(F(1,28)=0.54$, $M S E=3392.27, p=0.47)$, sagittal $(F(2,112)=0.68, M S E=$ $235.13, p=0.51)$, or lateral $(F(2,112)=2.90, \quad M S E=$ $830.89, p=0.08)$ was not significant. For standard P2 amplitudes, no significant main effect of group $(F(1$, $28)=0.23, M S E=3.18, p=0.63)$ or gender $(F(1,28)=$ 2.30, $M S E=31.63, p=0.14)$ was detected, but of sagittal $(F(2,112)=6.00, M S E=10.19, p<0.01)$ and lateral $(F(2$, $112)=11.09, M S E=9.98, p<0.01)$ sites were all significant. The standard P2 amplitudes were more pronounced at central sites $(2.5 \mu \mathrm{V} \pm 0.3)$ compared with those at frontal $(1.9 \mu \mathrm{V} \pm 0.3, p<0.01 ; 95 \% \mathrm{CI}[0.2,1.1])$ and parietal $(2.0 \mu \mathrm{V} \pm 0.2, p=0.03$; $95 \% \mathrm{CI}[0.1,1.0])$; at central $(2.5 \mu \mathrm{V} \pm 0.3)$ sites compared with those at left $(2.0 \mu \mathrm{V} \pm$ $0.2, p<0.01 ; 95 \% \mathrm{CI}[0.2,0.8])$ and right $(1.8 \mu \mathrm{V} \pm 0.2$, $p<0.01 ; 95 \%$ CI $[0.3,1.0])$.

\section{Morphology triggered by target stimuli}

In each participant, the N1, P2, N2, P3 (but not N4) to the target stimuli were clear.

\section{N1 component}

For target N1 latencies, there was no significant main effect of group $(F(1,28)=2.52, M S E=8990.30, p=0.12)$, sagittal $(F(2,112)=2.89, M S E=423.23, p=0.06)$ or lateral $(F(2,112)=0.31, M S E=34.37, p=0.74)$ either, but significant gender effect $(F(1,28)=6.65, M S E=23685.54, p=$ 0.02) was found, with prolonged N1 latencies in females (152.3 ms \pm 5.6 ; $95 \%$ CI $[3.9,34.0])$ compared with those 


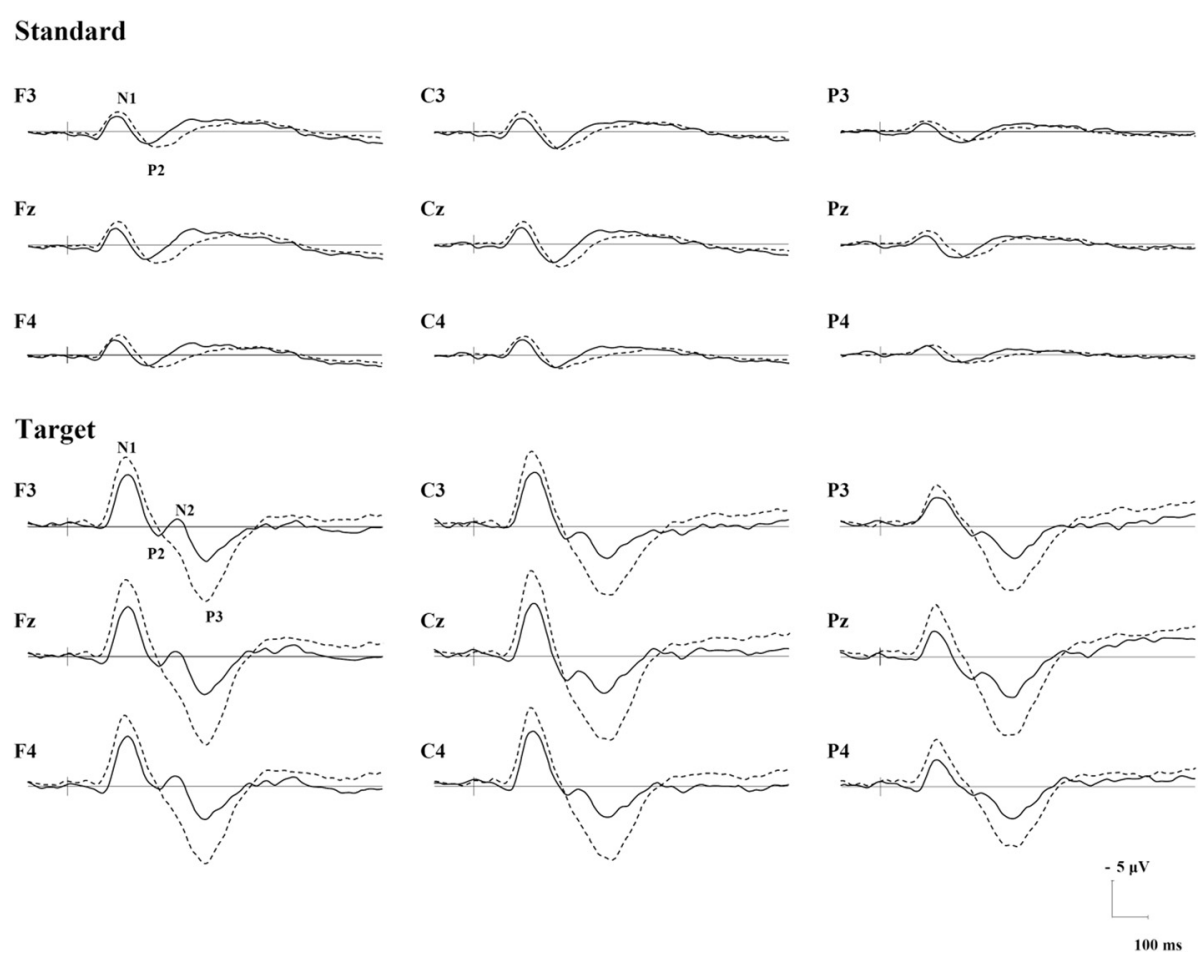

Fig. 1 ERP grand averages in controls and schizophrenia at nine electrode sites. Controls are presented in dashed $(n=16)$, and schizophrenia in solid $(n=16)$ lines

in males (133.4 $\mathrm{ms} \pm 4.8)$. For target $\mathrm{N} 1$ amplitudes, significant main effects of group $(F(1,28)=6.81, M S E=627.10$, $p=0.01)$ and of sagittal sites $(F(2,112)=40.88, M S E=$ $612.90, p<0.01)$, but not of gender $(F(1,28)=0.20, M S E=$ 18.29, $p=0.66)$ or of lateral sites $(F(2,112)=3.02, M S E=$ 32.24, $p=0.08)$ were detected. The target N1 amplitudes were more pronounced at frontal $(-11.1 \mu \mathrm{V} \pm 0.8, p<0.01$; $95 \% \mathrm{CI}[2.7,6.0])$ and central $(-11.5 \mu \mathrm{V} \pm 0.8, p<0.01$; $95 \%$ CI $[3.3,6.3])$ sites compared with those at parietal $(-6.8 \mu \mathrm{V} \pm 0.5)$, and was decreased in schizophrenia $(-8.2 \mu \mathrm{V} \pm 0.9)$ compared with those in controls $(-11.3 \mu \mathrm{V} \pm 0.8 ; 95 \% \mathrm{CI}[0.7,5.5])$ (Table 2).

\section{P2 component}

For target P2 latencies, no significant effect of group $(F(1,28)=1.21, M S E=5772.50, p=0.28)$, gender $(F(1$, $28)=4.00, M S E=19091.32, p=0.06)$, sagittal $(F(2,112)=$ 3.16, $M S E=698.30, p=0.06)$ or lateral $(F(2,112)=0.48$, $M S E=46.24, p=0.55$ ) was detected (Table 2). For target P2 amplitudes, main effect of group $(F(1,28)=0.24$, $M S E=67.55, p=0.63)$ or gender $(F(1,28)=0.64, M S E=$ 176.07, $p=0.43$ ) was not significant, while main effects of lateral $(F(2,112)=7.02, M S E=152.49, p<0.01)$, and of sagittal $(F(2,112)=14.50, M S E=107.78, p<0.01)$ were detected. The target $\mathrm{P} 2$ amplitudes were more pronounced at central sites $(3.7 \mu \mathrm{V} \pm 1.3)$ compared to those at left $(1.9 \mu \mathrm{V} \pm 0.9, p<0.01 ; 95 \% \mathrm{CI}[0.7,3.0])$ and at right
$(8.9 \mu \mathrm{V} \pm 0.8, p<0.01 ; 95 \% \mathrm{CI}[0.6,2.4])$, and were decreased at frontal sites $(1.0 \mu \mathrm{V} \pm 1.0)$ compared to those at parietal $(3.6 \mu \mathrm{V} \pm 1.0 ; 95 \% \mathrm{CI}[0.7,4.5])$ (Table 2).

\section{N2 component}

For N2 latencies, significant group $(F(1,28)=7.59$, $M S E=50393.81, p=0.01)$ and gender effects $(F(1,28)=$ 4.75, $M S E=31539.64, p=0.04)$ were found, with prolonged N2 latencies in females $(266.0 \mathrm{~ms} \pm 7.6 ; 95 \% \mathrm{CI}$ [1.3, 42.4]) compared with those in males (244.2 $\mathrm{ms} \pm 6.6)$, and in schizophrenia (268.9 ms \pm 7.3 ; $95 \%$ CI [7.0, 48.2]) compared with that in controls $(241.3 \mathrm{~ms} \pm 6.8)$. There was no significant main effect of sagittal $(F(2,112)=0.003$, $M S E=0.877, p=1.00)$, or lateral $(F(2,112)=2.97, M S E=$ 249.50, $p=0.06)$ sites (Table 2). For N2 amplitudes, no group $(F(1,28)=0.47, M S E=146.09, p=0.50)$ or gender $(F(1,28)=0.06, M S E=17.16, p=0.82)$ effect was detected, but main effects of sagittal $(F(2,112)=11.72, M S E=$ 267.57, $p<0.01)$, and of lateral $(F(2,112)=8.15, M S E=$ $58.22, p<0.01)$ sites were significant. The N2 amplitudes were more pronounced at frontal $(-1.5 \mu \mathrm{V} \pm 1.2)$ compared with those at central $(1.0 \mu \mathrm{V} \pm 1.3, p<0.01$; $95 \% \mathrm{CI}[0.6,4.3])$ and parietal $(1.8 \mu \mathrm{V} \pm 1.0, p<0.01$; $95 \% \mathrm{CI}[1.2,5.5])$ sites, were decreased at central (1.4 $\mu \mathrm{V} \pm 1.3, p<0.05)$ compared with those at left $(0.0 \mu \mathrm{V} \pm 0.9, p=0.01 ; 95 \% \mathrm{CI}[0.2,2.6])$ and right $(0.0 \mu \mathrm{V} \pm 1.0, p<0.01 ; 95 \% \mathrm{CI}[0.3,2.4])$ sites (Table 2). 
Table 2 Latencies and amplitudes of ERP components to target stimuli in controls and schizophrenia

\begin{tabular}{|c|c|c|c|c|}
\hline \multirow[t]{3}{*}{ Site } & \multicolumn{4}{|l|}{ N1 } \\
\hline & \multicolumn{2}{|l|}{ Latency } & \multicolumn{2}{|l|}{ Amplitude } \\
\hline & Controls & Schizophrenia & Controls & Schizophrenia \\
\hline F3 & $139.45 \pm 21.76$ & $141.46 \pm 14.05$ & $-13.48 \pm 7.99$ & $-9.18 \pm 3.42$ \\
\hline $\mathrm{Fz}$ & $140.91 \pm 21.14$ & $147.02 \pm 27.97$ & $-12.81 \pm 5.02$ & $-8.63 \pm 3.89 *$ \\
\hline F4 & $140.24 \pm 19.10$ & $143.72 \pm 20.69$ & $-11.50 \pm 4.09$ & $-8.55 \pm 4.62$ \\
\hline C3 & $139.14 \pm 21.19$ & $146.22 \pm 26.66$ & $-12.60 \pm 4.41$ & $-9.96 \pm 3.38$ \\
\hline $\mathrm{Cz}$ & $137.74 \pm 17.17$ & $144.21 \pm 27.19$ & $-14.00 \pm 6.06$ & $-9.52 \pm 3.60^{*}$ \\
\hline C4 & $138.35 \pm 16.93$ & $144.27 \pm 29.15$ & $-12.18 \pm 4.60$ & $-9.18 \pm 3.57^{*}$ \\
\hline P3 & $132.19 \pm 17.84$ & $140.55 \pm 30.68$ & $-7.27 \pm 2.79$ & $-5.74 \pm 2.58$ \\
\hline $\mathrm{Pz}$ & $133.53 \pm 18.37$ & $141.77 \pm 35.92$ & $-9.04 \pm 3.45$ & $-5.34 \pm 2.65^{* *}$ \\
\hline \multirow[t]{4}{*}{ P4 } & $136.40 \pm 19.74$ & $139.88 \pm 27.93$ & $-7.42 \pm 2.55$ & $-4.93 \pm 2.74^{*}$ \\
\hline & \multicolumn{4}{|l|}{ P2 } \\
\hline & Latency & & Amplitude & \\
\hline & Controls & Schizophrenia & Controls & Schizophrenia \\
\hline F3 & $220.48 \pm 27.61$ & $225.81 \pm 13.90$ & $0.29 \pm 4.57$ & $1.84 \pm 4.76$ \\
\hline $\mathrm{Fz}$ & $218.95 \pm 27.64$ & $225.57 \pm 21.76$ & $0.56 \pm 6.98$ & $2.15 \pm 5.40$ \\
\hline F4 & $219.38 \pm 28.54$ & $225.45 \pm 21.93$ & $0.48 \pm 5.78$ & $0.83 \pm 4.49$ \\
\hline $\mathrm{C} 3$ & $223.71 \pm 28.28$ & $229.54 \pm 16.73$ & $1.51 \pm 6.63$ & $2.85 \pm 5.90$ \\
\hline $\mathrm{Cz}$ & $223.35 \pm 33.24$ & $229.05 \pm 21.91$ & $3.72 \pm 10.13$ & $4.75 \pm 7.85$ \\
\hline C4 & $226.28 \pm 33.57$ & $229.60 \pm 21.26$ & $1.69 \pm 6.86$ & $1.97 \pm 5.33$ \\
\hline P3 & $218.77 \pm 29.20$ & $230.63 \pm 16.16$ & $3.06 \pm 4.93$ & $2.71 \pm 4.88$ \\
\hline 12 & $218.77 \pm 28.97$ & $223.92 \pm 21.44$ & $4.84 \pm 6.91$ & $5.33 \pm 4.61$ \\
\hline P4 & $222.98 \pm 31.98$ & $225.38 \pm 22.96$ & $2.50 \pm 5.00$ & $2.59 \pm 5.19$ \\
\hline
\end{tabular}

N2

Latency

Controls

F3 $243.83 \pm 38.62$

$\mathrm{Fz} \quad 243.40 \pm 37.07$

F4 $245.66 \pm 35.07$

C3 $\quad 242.79 \pm 38.83$

$\mathrm{Cz} \quad 243.40 \pm 38.78$

C4 $241.88 \pm 35.60$

P3 $242.97 \pm 39.60$

$\mathrm{Pz} \quad 246.45 \pm 35.50$

P4 $244.19 \pm 39.32$

P3

Latency

Controls

F3 $340.39 \pm 19.76$

Schizophrenia

Amplitude

Controls

$10.71 \pm 9.06$

Schizophrenia

$333.29 \pm 24.25$

$14.19 \pm 6.63$

$4.85 \pm 5.30^{*}$

Fz $\quad 334.29 \pm 21.32$

$335.00 \pm 24.84$

F4 $336.79 \pm 20.98$

$335.42 \pm 29.35$
Table 2 Latencies and amplitudes of ERP components to target stimuli in controls and schizophrenia (Continued)

\begin{tabular}{lllll}
\hline C3 & $330.57 \pm 28.50$ & $324.07 \pm 26.16$ & $11.88 \pm 5.81$ & $4.18 \pm 4.05^{* *}$ \\
Cz & $323.36 \pm 36.69$ & $320.84 \pm 27.69$ & $14.54 \pm 7.98$ & $5.61 \pm 4.60^{* *}$ \\
C4 & $328.80 \pm 31.31$ & $329.26 \pm 32.19$ & $12.88 \pm 5.58$ & $4.96 \pm 4.43^{* *}$ \\
P3 & $325.26 \pm 29.55$ & $328.16 \pm 23.97$ & $11.07 \pm 4.13$ & $4.70 \pm 4.84^{* *}$ \\
Pz & $322.14 \pm 31.82$ & $328.47 \pm 30.16$ & $13.67 \pm 5.46$ & $6.16 \pm 4.00^{* *}$ \\
P4 & $330.08 \pm 27.20$ & $330.24 \pm 34.17$ & $10.81 \pm 4.49$ & $5.18 \pm 3.67^{* *}$ \\
* ${ }^{*}<<.05,{ }^{* *} p<.01$ vs controls; sample sizes of controls and schizophrenia were \\
both 16. Latencies (in $\mathrm{ms}$ s) and amplitudes (in $\mu \mathrm{V}$ ) were presented as mean $\pm S D$
\end{tabular}

\section{P3 component}

For P3 latencies, no significant effect of group $(F(1,28)=$ $0.01, M S E=62.79, p=0.92)$, gender $(F(1,28)<0.01$, $M S E=0.06, p=1.00)$ or lateral $(F(2,112)=2.87, M S E=$ 581.59, $p=0.07)$ was detected, but significant main effect of sagittal $(F(2,112)=7.58, M S E=3357.89, p<0.01)$ was detected, with prolonged latencies at front sites (335.9 $\mathrm{ms} \pm 4.2$ ) compared with those at central (326.0 $\mathrm{ms} \pm$ $5.5, p=0.01 ; 95 \% \mathrm{CI}[2.3,17.7])$ and parietal $(326.9 \mathrm{~ms} \pm$ $5.3, p=0.03$; $95 \%$ CI $[0.7,17.4]$ ) sites (Table 2).

For P3 amplitudes, main effects of group $(F(1,28)=20.29$, $M S E=3638.96, p<0.01)$ and lateral sites $(F(2,112)=10.98$, $M S E=158.89, p<0.01)$ were detected, while the main effects of gender $(F(1,28)=1.54, M S E=276.17, p=0.23)$ and of sagittal sites $(F(2,112)=0.13, M S E=4.21, p=0.80)$ were not significant. The P3 amplitudes were more pronounced at central sites $(10.4 \mu \mathrm{V} \pm 1.0)$ compared to those at left $(8.0 \mu \mathrm{V} \pm 0.9, p<0.01 ; 95 \% \mathrm{CI}[0.9,3.8])$ and at right $(8.9 \mu \mathrm{V} \pm 0.8, p<0.01 ; 95 \% \mathrm{CI}[0.6,2.4])$, and were also decreased in schizophrenia $(5.3 \mu \mathrm{V} \pm 1.2)$ compared to those in controls $(12.8 \mu \mathrm{V} \pm 1.1 ; 95 \%$ CI $[4.0,10.8])$ (Table 2).

\section{Source analyses}

The source reconstruction of N1, P2 and N2 elicited by word illusion segments showed maximal activated areas at right parahippocampal gyrus (MNI coordinates: $x=29$, $y=-10, \quad z=-14 ;$ Brodmann area 28), right fusiform gyrus $(\mathrm{x}=46, \mathrm{y}=-30, \mathrm{z}=-21$; Brodmann area 20) and right insula $(x=43, y=9, z=7$; Brodmann area 13) respectively in controls, while at right fusiform gyrus $(x=46$, $y=-30, z=-21$; Brodmann area 20), right parahippocampal gyrus $(x=29, y=-10, z=-14$; Brodmann area 28) and left fusiform gyrus $(x=-44, y=-32, z=-21$; Brodmann area 20 ) respectively in schizophrenia.

The source reconstruction of P3 elicited by word illusion segments showed activated areas included bilateral temporal lobes, parietal lobe and cingulate cortex in both groups (Fig. 2). Specifically, the P3 source having maximal activity was at left inferior temporal gyrus (MNI coordinates: $\mathrm{x}=-50, \mathrm{y}=-7, \mathrm{z}=-41$; Brodmann Area 20) in controls and at left postcentral gyrus $(x=-17, y=-56$, 


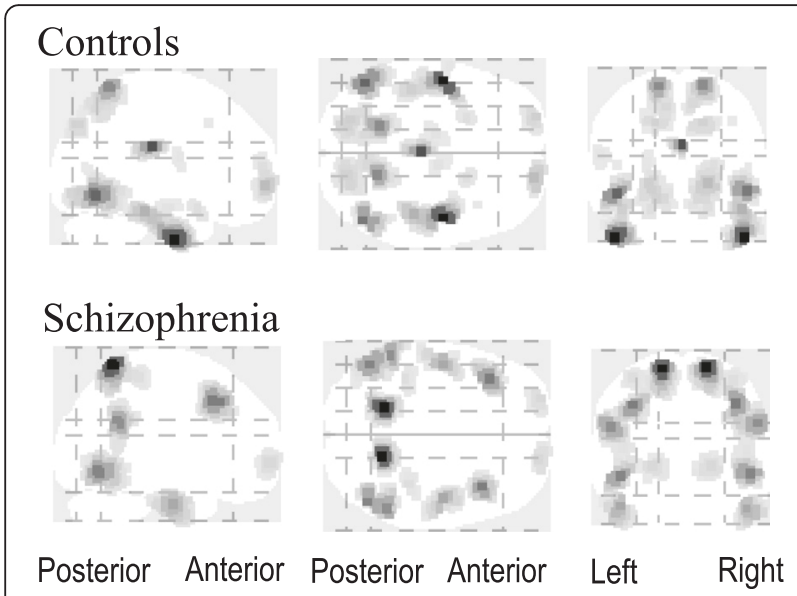

Fig. 2 P3 source reconstruction (maximum intensity projections) in controls and schizophrenia

$\mathrm{z}=67$; Brodmann area 7) in schizophrenia. Moreover, the source level statistical analyses showed a significant reduction of activity $(\mathrm{p}<0.01)$ in left inferior temporal cortex in schizophrenia compared with that in controls (Fig. 3).

\section{Relationship between ERP and clinical data}

The correlation test showed some associations between N1 amplitude and the PANSS scales (for detailed data, please see Additional file 1), but only paranoid scale score was significantly correlated with $\mathrm{N} 1$ amplitude at parietal area (P3, $r=.66, p=0.005 ; \mathrm{Pz}, r=.77, p=0.001 ; \mathrm{P} 4, r=.618$, $p=0.011)$ according to our ad hoc criteria. The scores of positive scale and thinking disorder, which contain the items of hallucinatory behavior, were not related to any ERP components (including those to the standard stimuli).

\section{Discussion}

As hypothesized, we have found that the P3 elicited by the Deutsch "high-low" word illusion was significantly reduced and its maximal source located at a different brain area in patients with schizophrenia than those in the healthy volunteers in the present study. In combination with the decreased $\mathrm{N} 1$ and prolonged $\mathrm{N} 2$ components in schizophrenia, the findings suggested an impaired processing of the stimulus within a very short time window which might be linked with the pathology in AVHs. This is the first study to illustrate the dynamic changes to an illusion, in a time window of N1-P3, in schizophrenia.

The reaction times to the target stimuli were prolonged in schizophrenia compared with those in controls, which was consistent with previous studies [33] on the one hand. Together with reduced P3, the prolongation indicated a breakdown in the preparatory brain state which was critical for stimulus processing and later motor execution [48] in schizophrenia on the other hand.

A frontal-central scalp distribution of the standard/ target N1, a more central standard/target P2, and a frontal-bilateral distributed N2 were also consistent with the previous documentation [49-52]. The reduced auditory target $\mathrm{N} 1$ has been reported in schizophrenia previously $[49,50]$. The lowered N1 was thought to reflect the impaired ability to filter out irrelevant information in patients with schizophrenia [53, 54], as well as the lowered competition ability between auditory probes and hallucinations for auditory resources in psychiatric patients [25]. Moreover, as an exogenous component representing the early auditory processing, the N1 reduction also reflects the abnormalities in frontal-temporal lobe [55]. Similarly, the shortened standard-P2 latencies in patients replicated previous findings $[52,56,57]$, indicating a faster processing speed for non-targets [56], which might reflect the impaired attention shifting to task-irrelevant stimuli. The prolonged N2 latencies in patients also replicated the results in the first-episode schizophrenia [58], which indicated a delayed stimulus-classification time in this pathology.

Similar to the scalp-distribution of the classical P3 [59], the P3 in our study was midline-distributed. The P3 reduction in our schizophrenia group was also consistent with previous researches [30-32], indicating a high-level, attention-dependent cognitive deficit when discriminating stimuli in the disorder [60]. This impairment of attentional allocation was associated with left temporoparietal cortices, which was involved in auditory-verbal imagery
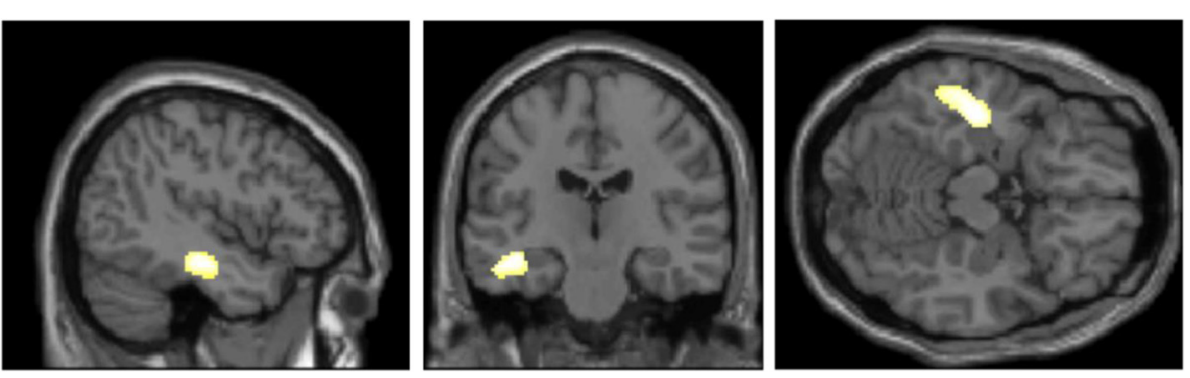

Fig. 3 Source level statistical parametric maps displaying decreased P3 activations in schizophrenia vs controls. Significant P3 source reductions were at left inferior temporal cortex [MNI coordinates: $x=-44, y=-2, z=-34, t=3.14, p=0.002]$ 
monitoring as demonstrated in schizophrenia [61]. Ford et al. [25] also interpreted the diminished classical P3 in patients with schizophrenia with auditory hallucinations as they preferentially attended to voices through the internal auditory channels, resulting in insufficient cortical resources to process an external stimulus.

When processing the Deutsch "high-low" word illusion, both our groups displayed activated areas of the bilateral temporal lobe, parietal lobe and cingulate cortex. Although the activation in schizophrenia was not specific, previous results have demonstrated that patients with schizophrenia with persistent hallucinations including AVHs exhibited grey matter volume decrements in the left or bilateral inferior temporal gyrus $[62,63]$, and their dysfunctions in speech or AVHs generation [18]. Moreover, an increased activity in the same area was found in schizophrenia patients prone to auditory hallucinations [64]. These investigations suggested that the impairment might be due to the endogenous cortical activity which impeded the processing of external stimulus.

In healthy participants, the left inferior temporal gyrus is involved in the language and semantic memory processing [65], such as the mental imagery tasks using linguistic cues [66], the mental recall of words [67], and the word generation test $[68,69]$. Our finding that the left inferior temporal gyrus was activated in the healthy volunteers might be explained by these studies. In addition, it might disclose some mechanisms behind the illusiontriggered word-generating processes in normal people [17].

In schizophrenia, the activity at postcentral gyrus was reported in patients performing auditory oddball task [70], and the activity in similar brain area was documented in patients involved in the auditory verbal imagery test [71]. These activiations were associated with the somatic [72] and auditory [73] hallucination processing, and even consistently with the processing of AVHs in schizophrenia $[20,74,75]$. Another recent study on the impaired attentional modulation in the first-episode psychosis, where patients misidentified their own speech as of others, also has shown an activation of the left postcentral gyrus when patients were judging the speech to be selfgenerated or not [76]. Falkenberg et al. [77] suggested that the activation of the postcentral gyrus implied a higher auditory processing and influenced by the attentional mechanisms. Considering the documentation, the putative P3 source at postcentral gyrus in the present study might reflect a compensatory cerebral functioning to discriminate external from internal stimulus-sources in schizophrenia. In addition, with joint independent component analysis applied in an auditory oddball paradigm integrating ERP and fMRI data, Mangalathu-Arumana et al. [78] found that the activity of the left postcentral gyrus was consistent with the relationship between mean motor response time and the P3 amplitude. In this case, the delayed reaction time to the Deutsch "high-low" word illusion in our schizophrenia group fitted nicely with the left postcentral gyrus activation for the P3 source.

The N1 amplitude at parietal area was found correlated with the paranoid scale in patients with schizophrenia, which was consistent with the finding that $\mathrm{N} 1$ amplitude was reduced (more positive proneness) in these patients [79], and in people with more delusion-like ideations [80]. As N1 reflected auditory detection and discrimination [81], the reduced N1 suggested that people with paranoia might not pay attention to the target stimuli. Instead, their attention was redirected toward the surrounding environment to look for the false "hidden goal" [80]. The altered attention to the Deutsch "high-low" word illusion was also in line with a behavioral finding that the paranoid personality disorder patients reported more meaningful Chinese words when listening to the illusion [17].

However, one has to bear in mind the major design flaws of our study. Firstly, we recruited 16 healthy volunteers from medical staff and community, who might not represent a general population. Our patients were with auditory hallucination experience but without onsite hallucination-attack during the test. It remains unknown how the ERPs would be in patients with schizophrenia of either hallucination-free or under hallucination-attack. Therefore, our current results cannot be generalized to other kinds of schizophrenia or mental disorders. Secondly, we did not measure personality disorder functioning styles in patients, nor did we correlate their styles with the reported meaningful Chinese words immediately after ERP tests, due to the small sample size and the small number of meaningful words reported. Thirdly, we did not use a hallucination as a target stimulus, but simply used an illusion to trigger ERPs, and we omitted to study the frequencies and contents of AVHs in our patients. Certainly, such ideas merit further investigation. Nevertheless, we found deformed ERPs and different cerebral sources to the Deutsch "high-low" word illusion in patients.

\section{Conclusions}

Our results addressed the cognitive problems in schizophrenia relating to the illusion, thus deepened our knowledge of hallucination processing in schizophrenia. Moreover, our study had illustrated a whole process of cerebral information processing from N1 to $\mathrm{P} 3$, indicating this illusion had triggered a dynamic cerebral response which might be similar to that of the AVHs had engaged.

\section{Additional files}

Additional file 1: Table S1. Pearson correlations between ERP latencies and amplitudes and PANSS scores in schizophrenia $(n=16)$. (DOCX $26 \mathrm{~kb})$ 


\section{Abbreviations}

AVHs: auditory verbal hallucinations; $\mathrm{CT}$ : computed tomography; ERPs: event-related potentials; fMRI: functional magnetic resonance imaging; MRI: magnetic resonance imaging; ms: millisecond; PANSS: positive and negative syndrome scale; $\mu \mathrm{V}$ : microvolt.

\section{Competing interests}

The authors declare that they have no competing interests.

\section{Authors' contributions}

YX participated in its design, performed the measurement, interpretation of the data and drafted in the manuscript; HC conceived of the study, performed the measurement, interpretation of the data and drafted in the manuscript; BZ helped performed the measurement and analysed the data; QG helped performed the measurement and analysed the data; HF performed the measurement; $L Z$ participated in the design and helped performed the measurement; HM performed the measurement; YZ performed the measurement; WW conceived and designed the study, interpretation of the data and coordination the manuscript writing; All authors read and approved the final version of the manuscript.

\section{Acknowledgements}

The study was supported by a grant from the Natural Science Foundation of China (No. 30971042) to Dr. W. Wang. YX and HC contributed equally to the work described in the report.

\section{Author details}

${ }^{1}$ Department of Clinical Psychology and Psychiatry, School of Public Health, Zhejiang University College of Medicine, Hangzhou, China. ${ }^{2}$ Department of Psychiatry, Second Affiliated Hospital, Zhejiang University College of Medicine, Hangzhou, China. ${ }^{3}$ Department of Clinical Psychology, Mental Health Center, Zhejiang University College of Medicine, Hangzhou, China.

Received: 30 July 2015 Accepted: 12 February 2016 Published online: 18 February 2016

\section{References}

1. Kalkstein S, Hurford I, Gur RC. Neurocognition in schizophrenia. Curr Top Behav Neurosci. 2010;4:373-90.

2. Barch DM, Ceaser A. Cognition in schizophrenia: core psychological and neural mechanisms. Trends Cogn Sci. 2012;16:27-34.

3. Salisbury DF. Semantic activation and verbal working memory maintenance in schizophrenic thought disorder: insights from electrophysiology and lexical ambiguity. Clin EEG Neurosci. 2008;39(2):103-7.

4. Kuperberg GR, Kreher DA, Ditman T. What can event-related potentials tel us about language, and perhaps even thought, in schizophrenia? Int $J$ Psychophysiol. 2010;75(2):66-76.

5. Mohammad OM, DeLisi LE. N400 in schizophrenia patients. Curr Opin Psychiatry. 2013;26(2):196-207.

6. Løberg EM, Jørgensen HA, Kroken RA, Johnsen E. Auditory verbal hallucinations reflect stable auditory attention deficits: a prospective study. Cogn Neuropsychiatry. 2015;20(1):81-94.

7. Badcock JC. The cognitive neuropsychology of auditory hallucinations: a parallel auditory pathways framework. Schizophr Bull. 2010;36:576-84.

8. Waters F, Allen P, Aleman A, Fernyhough C, Woodward TS, Badcock JC, et al. Auditory hallucinations in schizophrenia and nonschizophrenia populations: a review and integrated model of cognitive mechanisms. Schizophr Bull. 2012;38(4):683-93.

9. Hoskin R, Hunter MD, Woodruff PW. The effect of psychological stress and expectation on auditory perception: A signal detection analysis. Br J Psychol. 2014;105(4):524-46.

10. Daalman K, Verkooijen S, Derks EM, Aleman A, Sommer IE. The influence of semantic top-down processing in auditory verbal hallucinations. Schizophr Res. 2012;139(1-3):82-6.

11. Bentall RP. The illusion of reality: a review and integration of psychological research on hallucinations. Psychol Bull. 1990;107:82-95.

12. Al-Issa I. The illusion of reality or the reality of illusion. Hallucinations and culture. Br J Psychiatry. 1995;166:368-73.

13. Deutsch D. An auditory illusion. Nature. 1974:251:307-9.

14. Deutsch D. Musical illusions. Sci Am. 1975;233:92-104.
15. Deutsch D. Musical illusions and paradoxes (compact disc). La Jolla: Philomel Records; 1995.

16. Xu Y, Zhu J, Chen W, Chai H, He W, Wang W. Personality correlates of reporting Chinese words from the Deutsch "high-low" word illusion by Chinese-speaking people. Neurosci Bull. 2012;28:240-6.

17. Xu Y, Fan H, Gao Q, Mao H, Zhang Y, Chen WZ, et al. Reporting meaningful Chinese words while listening to the Deutsch word illusions in Chinese patients with cluster A personality disorders. J Psychiatry. 2015;18:1000197.

18. Stephane M, Barton S, Boutros NN. Auditory verbal hallucinations and dysfunction of the neural substrates of speech. Schizophr Res. 2001;50:61-78.

19. Jardri R, Pouchet A, Pins D, Thomas P. Cortical activations during auditory verbal hallucinations in schizophrenia: a coordinate-based meta-analysis. Am J Psychiatry. 2011:168:73-81.

20. Kuhn S, Gallina J. Quantitative meta-analysis on state and trait aspects of auditory verbal hallucinations in schizophrenia. Schizophr Bull. 2012;38:779-86.

21. Lennox BR, Bert S, Park G, Jones PB, Morris PG. Spatial and temporal mapping of neural activity associated with auditory hallucinations. Lancet. 1999:353:644.

22. Lennox BR, Park SB, Medley I, Morris PG, Jones PB. The functional anatomy of auditory hallucinations in schizophrenia. Psychiatry Res. 2000:100:13-20.

23. Shergill SS, Brammer MJ, Williams SC, Murray RM, McGuire PK. Mapping auditory hallucinations in schizophrenia using functional magnetic resonance imaging. Arch Gen Psychiatry. 2000a;57:1033-8.

24. van de Ven VG, Formisano E, Roder CH, Prvulovic D, Bittner RA, Dietz MG, et al. The spatiotemporal pattern of auditory cortical responses during verbal hallucinations. Neuroimage. 2005;27:644-55.

25. Ford JM, Dierks T, Fisher DJ, Herrmann CS, Hubl D, Kindler J, et al. Neurophysiological studies of auditory verbal hallucinations. Schizophr Bull. 2012;38:715-23.

26. Boyd JE, Patriciu I, McKinnon MC, Kiang M. Test-retest reliability of N400 event-related brain potential measures in a word-pair semantic priming paradigm in patients with schizophrenia. Schizophr Res. 2014;158(1-3):195-203.

27. Besche-Richard C, lakimova G, Hardy-Baylé MC, Passerieux C. Behavioral and brain measures (N400) of semantic priming in patients with schizophrenia: test-retest effect in a longitudinal study. Psychiatry Clin Neurosci. 2014;68(5):365-73.

28. Armstrong GA, Singhal A. Neural markers of automatic and controlled attention during immediate and delayed action. Exp Brain Res. 2011;213(1):35-48.

29. Dima D, Dillo W, Bonnemann C, Emrich HM, Dietrich DE. Reduced P300 and P600 amplitude in the hollow-mask illusion in patients with schizophrenia. Psychiatry Res. 2011:191(2):145-51.

30. Jeon YW, Polich J. Meta-analysis of P300 and schizophrenia: patients, paradigms, and practical implications. Psychophysiology. 2003;40:684-701.

31. Bramon E, Rabe-Hesketh S, Sham P, Murray RM, Frangou S. Meta-analysis of the P300 and P50 waveforms in schizophrenia. Schizophr Res. 2004;70:315-29.

32. Fisher DJ, Labelle A, Knott VJ. Auditory hallucinations and the P3a: attentionswitching to speech in schizophrenia. Biol Psychol. 2010;85(3):417-23.

33. McCarley RW, Faux SF, Shenton ME, Nestor PG, Adams J. Event-related potentials in schizophrenia: their biological and clinical correlates and a new model of schizophrenic pathophysiology. Schizophr Res. 1991:4:209-31.

34. Turetsky B, Colbath EA, Gur RE. P300 subcomponent abnormalities in schizophrenia: II. Longitudinal stability and relationship to symptom change. Biol Psychiatry. 1998:43:31-9.

35. Bruder G, Kayser J, Tenke C, Amador X, Friedman M, Sharif Z, et al. Left temporal lobe dysfunction in schizophrenia: event-related potential and behavioral evidence from phonetic and tonal dichotic listening tasks. Arch Gen Psychiatry. 1999;56:267-76.

36. O'Donnell BF, McCarley RW, Potts GF, Salisbury DF, Nestor PG, Hirayasu Y, et al. Identification of neural circuits underlying P300 abnormalities in schizophrenia. Psychophysiology. 1999;36:388-98.

37. McCarley RW, Salisbury DF, Hirayasu Y, Yurgelun-Todd DA, Tohen M Zarate $\mathrm{C}$, et al. Association between smaller left posterior superior temporal gyrus volume on magnetic resonance imaging and smaller left temporal P300 amplitude in first-episode schizophrenia. Arch Gen Psychiatry. 2002:59:321-31.

38. Turetsky BI, Calkins ME, Light GA, Olincy A, Radant AD, Swerdlow NR. Neurophysiological endophenotypes of schizophrenia: the viability of selected candidate measures. Schizophr Bull. 2007;33:69-94.

39. World Health Organization. The ICD-10 Classification of Mental and Behavioural Disorders: Clinical Descriptions and Diagnostic Guidelines. Geneva: WHO; 1992.

40. Kay SR, Flszbein A, Opfer LA. The positive and negative syndrome scale (PANSS) for schizophrenia. Schizophr Bull. 1987;13(2):261-76. 
41. Oldfield RC. The assessment and analysis of handedness: the Edinburgh inventory. Neuropsychologia. 1971;9:97-113.

42. Ille N, Berg P, Scherg M. Artifact correction of the ongoing EEG using spatial filters based on artifact and brain signal topographies. J Clin Neurophysiol. 2002;19:113-24

43. Friston K, Harrison L, Daunizeau J, Kiebel S, Phillips C, Trujillo-Barreto N, et al. Multiple sparse priors for the M/EEG inverse problem. Neurolmage. 2008;39:1104-20

44. Litvak V, Mattout J, Kiebel S, Phillips C, Henson R, Kilner J et al. EEG and MEG data analysis in SPM8. Comput Intell Neurosci. 2011. doi: 10.1155/2011/852961

45. Phillips C, Mattout J, Rugg MD, Maquet P, Friston KJ. An empirical Bayesian solution to the source reconstruction problem in EEG. Neurolmage. 2005;24:997-1011

46. Henson RN, Mattout J, Phillips C, Friston KJ. Selecting forward models for MEG source-reconstruction using model-evidence. Neurolmage. 2009;46:168-76.

47. Worsley KJ, Friston KJ. Analysis of fMRI time-series revisited-again. Neurolmage. 1995:2:173-81.

48. Reinhart RM, Mathalon DH, Roach BJ, Ford JM. Relationships between pre-stimulus gamma power and subsequent P300 and reaction time breakdown in schizophrenia. Int J Psychophysiol. 2011;79(1):16-24.

49. Ford JM, Mathalon DH, Kalba S, Marsh L, Pfefferbaum A. N1 and P300 abnormalities in patients with schizophrenia, epilepsy, and epilepsy with schizophrenialike features. Biol Psychiatry. 2001;49:848-60.

50. O'Donnell BF, Vohs JL, Hetrick WP, Carroll CA, Shekhar A. Auditory event-related potential abnormalities in bipolar disorder and schizophrenia. Int Psychophysiol. 2004;53:45-55.

51. Calhoun V, Wu L, Kiehl K, Eichele T, Pearlson G. Aberrant processing of deviant stimuli in schizophrenia revealed by fusion of FMRI and EEG Data. Acta Neuropsychiatr. 2010;22:127-38.

52. Salisbury DF, Collins KC, McCarley RW. Reductions in the N1 and P2 auditory event-related potentials in first-hospitalized and chronic schizophrenia. Schizophr Bull. 2010;36:991-1000.

53. Javitt DC, Sweet RA. Auditory dysfunction in schizophrenia: integrating clinical and basic features. Nature Reviews. Neuroscience. 2015;16(9):535-50.

54. Javitt DC, Freedman R. Sensory processing dysfunction in the personal experience and neuronal machinery of schizophrenia. Am J Psychiatry. 2015;172:17-31

55. Gallinat J, Mulert C, Bajbouj M, Herrmann WM, Schunter J, Senkowski D, et al. Frontal and temporal dysfunction of auditory stimulus processing in schizophrenia. Neurolmage. 2002;17:110-27.

56. Brown K, Gordon E, Williams L, Bahramali H, Harris A, Gray J, et al. Misattribution of sensory input reflected in dysfunctional target:non-target ERPs in schizophrenia. Psychol Med. 2000;30:1443-9.

57. Ferreira-Santos F, Silveira C, Almeida PR, Palha A, Barbosa F, Marques-Teixeira J. The auditory P200 is both increased and reduced in schizophrenia? A meta-analytic dissociation of the effect for standard and target stimuli in the oddball task. Clin Neurophysiol. 2012;123(7):1300-8.

58. Demiralp T, Üçok A, Devrim M, Isoglu-Alkaç Ü, Tecer A, Polich J. N2 and P3 components of event-related potential in first-episode schizophrenic patients: scalp topography, medication, and latency effects. Psychiatry Res. 2002:111:167-79.

59. Polich J. Updating P300: an integrative theory of P3a and P3b. Clin Neurophysiol. 2007:118:2128-48.

60. van der Stelt O, Frye J, Lieberman JA, Belger A. Impaired P3 generation reflects high-level and progressive neurocognitive dysfunction in schizophrenia. Arch Gen Psychiatry. 2004;61:237-48.

61. Papageorgiou C, Oulis P, Vasios C, Kontopantelis E, Uzunoglu N, Rabavilas A, et al. P300 alterations in schizophrenic patients experiencing auditory hallucinations. Eur Neuropsychopharmacol. 2004;14(3):227-36.

62. Onitsuka T, Shenton ME, Salisbury DF, Dickey CC, Kasai K, Toner SK, et al. Middle and inferior temporal gyrus gray matter volume abnormalities in chronic schizophrenia: an MRI study. Am J Psychiatry. 2004;161:1603-11.

63. O'Daly OG, Frangou S, Chitnis X, Shergill SS. Brain structural changes in schizophrenia patients with persistent hallucinations. Psychiatry Res. 2007;156:15-21.

64. Horacek J, Brunovsky M, Novak T, Skrdlantova L, Klirova M, Bubenikova-Valesova $V$, et al. Effect of low-frequency rTMS on electromagnetic tomography (LORETA) and regional brain metabolism (PET) in schizophrenia patients with auditory hallucinations. Neuropsychobiology. 2007:55:132-42.
65. Whitney C, Kirk M, O'Sullivan J, Lambon Ralph MA, Jefferies E. The neural organization of semantic control: TMS evidence for a distributed network in left inferior frontal and posterior middle temporal gyrus. Cereb Cortex. 2011;21:1066-75

66. Mellet E, Tzourio N, Denis M, Mazoyer B. Cortical anatomy of mental imagery of concrete nouns based on their dictionary definition. Neuroreport. 1998;9:803-8.

67. Nakamura K, Honda M, Okada T, Hanakawa T, Toma K, Fukuyama H, et al. Participation of the left posterior inferior temporal cortex in writing and mental recall of kanji orthography: a functional MRI study. Brain. 2000;123:954-67.

68. Chan AHD, Liu HL, Yip V, Fox PT, Gao JH, Tan LH. Neural systems for word meaning modulated by semantic ambiguity. Neurolmage. 2004;22:1128-33.

69. Rowan A, Liégeois F, Vargha-Khadem F, Gadian D, Connelly A, Baldeweg T. Cortical lateralization during verb generation: a combined ERP and fMRI study. Neurolmage. 2004:22:665-75.

70. Kiehl KA, Stevens MC, Celone K, Kurtz M, Krystal JH. Abnormal hemodynamics in schizophrenia during an auditory oddball task. Biol Psychiatry. 2005;57:1029-40.

71. Shergill SS, Bullmore E, Simmons A, Murray R, McGuire P. Functional anatomy of auditory verbal imagery in schizophrenic patients with auditory hallucinations. Am J Psychiatry. 2000b;157:1691-3.

72. Shergill SS, Cameron LA, Brammer MJ, Williams SC, Murray RM, McGuire PK. Modality specific neural correlates of auditory and somatic hallucinations. J Neurol Neurosurg Psychiatry. 2001;71:688-90.

73. Nenadic I, Smesny S, Schlosser RG, Sauer H, Gaser C. Auditory hallucinations and brain structure in schizophrenia: voxel-based morphometric study. $\mathrm{Br} \mathrm{J}$ Psychiatry. 2010;196:412-3.

74. Diederen KM, Neggers SF, Daalman K, Blom JD, Goekoop R, Kahn RS, et al. Deactivation of the parahippocampal gyrus preceding auditory hallucinations in schizophrenia. Am J Psychiatry. 2010;167:427-35.

75. van Lutterveld R, Diederen KM, Koops S, Begemann MJ, Sommer IE. The influence of stimulus detection on activation patterns during auditory hallucinations. Schizophr Res. 2013;145:27-32.

76. Kambeitz-Ilankovic L, Hennig-Fast K, Benetti S, Kambeitz J, Pettersson-Yeo W O'Daly $\mathrm{O}$, et al. Attentional modulation of source attribution in first-episode psychosis: A functional magnetic resonance imaging study. Schizophr Bull. 2012;39(5):1027-36.

77. Falkenberg LE, Specht K, Westerhausen R. Attention and cognitive control networks assessed in a dichotic listening fMRI study. Brain Cogn. 2011;76(2):276-85.

78. Mangalathu-Arumana J, Beardsley SA, Liebenthal E. Within-subject joint independent component analysis of simultaneous fMRI/ERP in an auditory oddball paradigm. Neurolmage. 2012:60(4):2247-57.

79. Kessler C, Steinberg A. Evoked potential variation in schizophrenic subgroups. Biol Psychiatry. 1989:26(4):372-80.

80. Prévost M, Rodier M, Lionnet C, Brodeur M, King S, Debruille JB. Paranoid induction reduces N400s of healthy subjects with delusional-like ideation. Psychophysiology. 2011;48(7):937-49.

81. Tomé D, Barbosa F, Nowak K, Marques-Teixeira J. The development of the $\mathrm{N} 1$ and N2 components in auditory oddball paradigms: a systematic review with narrative analysis and suggested normative values. J Neural Transm. 2015:122(3):375-91.

\section{Submit your next manuscript to BioMed Central and we will help you at every step:}

- We accept pre-submission inquiries

- Our selector tool helps you to find the most relevant journal

- We provide round the clock customer support

- Convenient online submission

- Thorough peer review

- Inclusion in PubMed and all major indexing services

- Maximum visibility for your research

Submit your manuscript at www.biomedcentral.com/submit 